\title{
The Arg-Gly-Asp-Containing, Solvent-Exposed Loop of Ptr ToxA Is Required for Internalization
}

\author{
Viola A. Manning, ${ }^{1}$ Sara M. Hamilton, ${ }^{1}$ P. Andrew Karplus, ${ }^{2}$ and Lynda M. Ciuffetti ${ }^{1}$ \\ ${ }^{1}$ Department of Botany and Plant Pathology and ${ }^{2}$ Department of Biochemistry and Biophysics, Oregon State University, \\ Corvallis 97331, U.S.A.
}

Submitted 17 July 2007. Accepted 30 October 2007.

Internalization of the proteinaceous host-selective toxin, Ptr ToxA (ToxA), into sensitive wheat mesophyll cells is correlated with toxin activity. The solvent-exposed, ArgGly-Asp (RGD)-containing loop of ToxA is a candidate for interaction with the plasma membrane, which is a likely prerequisite to toxin internalization. Based on the percentage of cells affected by a given number of ToxA molecules in a treatment zone, the number of ToxA molecules bound to high-affinity sites was estimated at $3 \times 10^{6}$ per cell and the Kd for binding was estimated to be near $1 \mathrm{nM}$. An improved heterologous expression method of proteins that contain mutations in ToxA, coupled with a newly developed semiquantitative bioassay, revealed that some amino acids in the RGD-containing loop contribute more to toxin activity than others. Protease protection assays that detect internalized protein and inhibition of toxin uptake indicated that, for each ToxA variant tested, the extent of toxin activity correlates with the amount of internalized protein. RGD-containing peptide inhibition of both activity and internalization supported these findings. These data support the hypothesis that ToxA interacts with a high-affinity binding site on wheat mesophyll cells through the RGDcontaining, solvent-exposed loop, resulting in toxin internalization and eventual cell death. The inability to detect phosphorylation of ToxA in vitro and in vivo suggests that a putative CKII phosphorylation site in the RGD-containing loop is required for internalization, not phosphorylation.

Additional keywords: inverse gene-for-gene, necrotroph, Pyrenophora tritici-repentis, receptor-mediated endocytosis

Ptr ToxA (syn. Ptr toxin, Ptr necrosis toxin, and ToxA) (Ciuffetti et al. 1998), is a 13.2-kDa (Tuori et al. 1995) proteinaceous host-selective toxin produced by the necrotrophic, foliar wheat pathogen Pyrenophora tritici-repentis (Ciuffetti and Tuori 1999; De Wolf et al. 1998; Strelkov and Lamari 2003). The host response to ToxA-producing isolates of $P$. triticirepentis follows an inverse gene-for-gene model for plantpathogen interactions (Lamari et al. 2002, 2003; Wolpert et al. 2002). The classical gene-for-gene model maintains that expression of an avirulence ( $A v r)$ gene in the pathogen and a corresponding resistance $(R)$ gene in the host initiates a resistance response (Flor 1971). This model is based primarily on inter-

Corresponding author: L. M. Ciuffetti; Telephone: +541-737-5267; Fax: +541-737-3573; E-mail: ciuffetL@ science.oregonstate.edu

* The $\boldsymbol{e}$-Xtra logo stands for "electronic extra" and indicates that a supplemental figure is published online. actions between biotrophic plant pathogens and their hosts (Glazebrook 2005). The inverse gene-for-gene model posits that expression of a gene by the pathogen and a corresponding gene in the host initiates a susceptible response. This is exhibited in the $P$. tritici-repentis-wheat interaction where host susceptibility to ToxA-producing isolates is governed by an unidentified gene, designated Tsnl (Anderson et al. 1999), on the 5BL chromosome (Faris et al. 1996; Stock et al. 1996) that confers sensitivity to ToxA (Gamba et al. 1998). Although the host gene that differentiates a ToxA-sensitive from -insensitive reaction has not been identified, ToxA has been shown to be internalized into ToxA-sensitive but not -insensitive wheat mesophyll cells, where it localizes to discreet cellular compartments and associates with chloroplasts (Manning and Ciuffetti 2005). Recently, it has been demonstrated that ToxA interacts with the chloroplast protein ToxABP1 (Manning et al. 2007), a homolog of Arabidopsis thylakoid factor1 (Thf1) (Wang et al. 2004). In addition, expression of ToxA in both sensitive and insensitive cells results in cell death (Manning and Ciuffetti 2005). Together, these data suggest that internalization is required for ToxA activity.

The PtrToxA gene encodes a pre-pro-protein containing a signal sequence for targeting to the secretory system (Ballance et al. 1996; Ciuffetti et al. 1997) and a small N-terminal domain required for proper folding (Tuori et al. 2000); both of these are cleaved to produce the mature, active toxin (C-terminal domain). ToxA contains several motifs that are critical for activity, including two putative casein kinase II (CKII) phosphorylation sites (Manning et al. 2004) and a "vitronectinlike" motif (Manning et al. 2004) containing an Arg-Gly-Asp (RGD) sequence that may be a cell-attachment site (Ciuffetti et al. 1997; Zhang et al. 1997). RGD cell-attachment sites have been shown to be important for protein-protein interactions at the plasma membrane in plants and animals (Gouget et al. 2006; Ruoslahti and Pierschbacher 1986). Crystal structure analysis of ToxA revealed a single-domain protein composed of a $\beta$-sandwich fold with part of the vitronectin-like sequence, including the RGD, on a solvent-exposed loop (Sarma et al. 2005). The solvent-exposed, RGD-containing loop of ToxA is a likely candidate for interaction at the cell surface (Ciuffetti et al. 1997; Manning and Ciuffetti 2005; Manning et al. 2004; Meinhardt et al. 2002; Sarma et al. 2005; Zhang et al. 1997); however, it is equally possible that it is important for intracellular interactions.

ToxA treatment of sensitive wheat induces cell death similar to that seen with inoculation by a ToxA-producing isolate (Ballance et al. 1989; Tomas et al. 1990; Tuori et al. 1995). ToxA treatment involves the introduction of toxin into the apoplastic space of a leaf, using pressure to distribute the toxin outward from the point of infiltration. Infiltration with a high 
concentration of toxin results in cell death throughout the treatment zone. When concentrations are decreased, cell death is centralized around the point of infiltration rather than throughout the entire treatment zone (Ballance et al. 1989; Tuori et al. 1995). In other words, when a low concentration of toxin is introduced into the leaf, toxin molecules are sequestered close to the infiltration site. This suggests that ToxA is interacting with a high-affinity receptor (Manning and Ciuffetti 2005), possibly through the RGD-containing loop (Ciuffetti et al. 1997; Manning and Ciuffetti 2005; Manning et al. 2004; Meinhardt et al. 2002; Sarma et al. 2005; Zhang et al. 1997). In this study, we utilize a semiquantitative bioassay to compare the activities of ToxA and ToxA protein variants and derive an estimate of the affinity and the number of ToxA binding sites on ToxA-sensitive cells. Furthermore, we demonstrate that the RGD-containing solvent-exposed loop is required for internalization and observe that the quantity of toxin internalized affects the extent of cell death.

\section{RESULTS}

\section{A semiquantitative ToxA bioassay.}

His-ToxA expressed in Escherichia coli accumulates in inclusion bodies and must be solubilized in a strong denaturant and refolded. In early work, we refolded His-ToxA prior to purification (method 1) (Manning et al. 2004; Tuori et al. 2000) but more recently (Manning and Ciuffetti 2005) have switched to purifying the protein prior to refolding (method 2) (Fig. 1). Although the two methods have similar yields, we noted that four mutant proteins (T137A, R140A, V143A, and E145A) that had been deemed inactive based on method 1 (Manning et al. 2004) showed some bioactivity when purified by method 2 . All recombinant His-ToxA variants used in this work were prepared by method 2 and were assessed for purity by sodium dodecyl sulfate polyacrylamide gel electrophoresis (SDSPAGE) analysis.

To better characterize the activity of recombinant ToxA variants compared with native ToxA, we have enhanced the information content of the standard bioassay. The assay is still based on the infiltration of a ToxA solution into sensitive wheat leaves, but the results are now quantified more fully. First, the relative size of symptom development was scored from 0 to 5 to reflect symptom coverage of the infiltration zone, where $0=0,1=0$ to $20,2=20$ to $40,3=40$ to $60,4=$ 60 to 80 , and $5=80$ to $100 \%$. Second, the relative severity of the symptom was scored from 0 to 5 , where 0 represents no symptom development and 5 complete necrosis. Third, the leaves were scored on each day to provide information on the time course of the response. Fourth, bioassays were performed with varying amounts of toxin because differences in toxin activity can be more sensitively measured when toxin is not present at saturating levels.

The value of this assay is illustrated by an assessment of the relative activities of recombinant His-ToxA and native ToxA (Fig. 2). For both native ToxA and His-ToxA, symptoms appear at day 1 on leaves infiltrated with 0.1 and $0.5 \mu \mathrm{M}$ but not $0.02 \mu \mathrm{M}$; however, both the relative size (Fig. 2A) and relative severity (Fig. 2B) of the symptoms induced by His-ToxA are slightly less than those of native ToxA. By day 5, leaves infiltrated with $0.5 \mu \mathrm{M}$ native ToxA or His-ToxA show similar levels of symptom development (Fig. 2A, B, and C). At 0.1 and $0.02 \mu \mathrm{M}$ His-ToxA, the portion of the infiltration zone affected is less than that of native ToxA (Fig. 2A); however, like native ToxA, maximum severity is achieved by day 5 (Fig. $2 \mathrm{~B}$ and C). Thus, it is at early time points and at nonsaturating levels of toxin treatment that a slight reduction in His-ToxA activity relative to native ToxA is evident. Consistent with this, leaves infiltrated with $0.004 \mu \mathrm{M}$ native ToxA consistently develop symptoms whereas leaves infiltrated with the same concentration of His-ToxA do not (Fig. 2C).

In addition to a decrease in the necrotic area in leaves treated with nonsaturating levels of His-ToxA, there is a difference at the margins of the necrotic areas when compared with the same concentrations of native ToxA. In leaves infiltrated with $0.1 \mu \mathrm{M}$ native ToxA, the symptom margins are well defined, whereas leaves infiltrated with the same concentration of His-ToxA have more diffuse edges, with slight symptom development extending well beyond the area of severest symptoms (Fig. 2D).
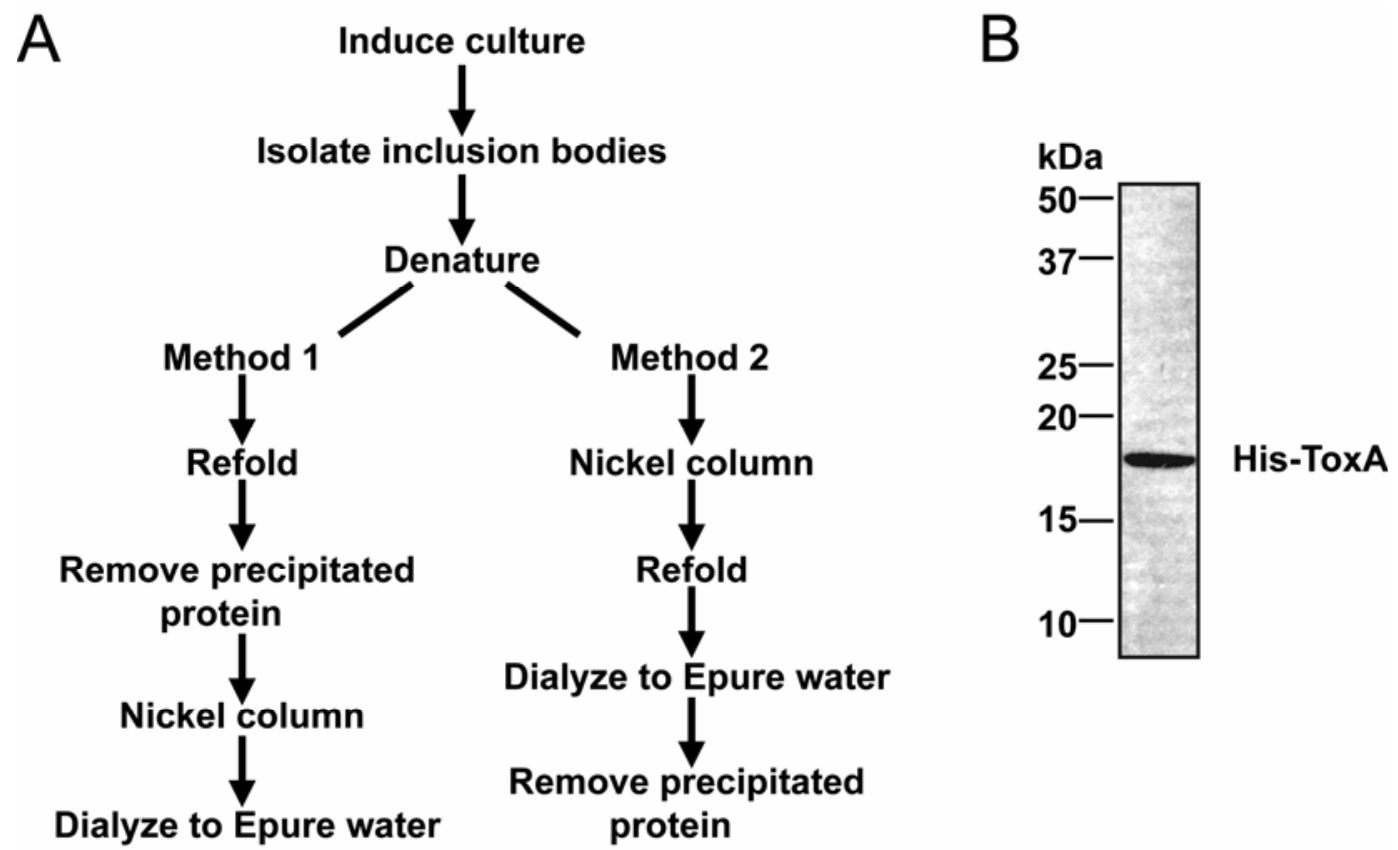

Fig. 1. His-ToxA heterologous expression in Escherichia coli. A, Schematic comparison of two refolding methods. B, Silver-stained sodium dodecyl sulfate polyacrylamide gel electrophoresis of $1 \mu \mathrm{g}$ of heterologously expressed protein produced by method 2 . Migration of molecular mass markers (kDa) indicated on the left. 


\section{Sensitive wheat has} an abundant high-affinity ToxA receptor.

For interpreting the semiquantitative bioassay results, it is important to consider events at the molecular level. First, during infiltration, the solution of ToxA spreads through the infiltrated region. If there is no ToxA interaction with a binding site then there will be a homogeneous concentration of ToxA throughout the region. However, if there are high-affinity binding sites for ToxA on the cell surface, then the leaf will act like an affinity matrix so that a gradient will result, with ToxA being concentrated near the point of infiltration and only extending further out as the inner receptors are saturated. In the latter case, a ToxA distribution is set up in the infiltration zone. As a result, the time course of symptom development in different areas of the zone reflects the rate at which the amount of ToxA present in that area kills cells. This will depend upon how effectively the protein can be internalized and how well it can interact with the appropriate intracellular target molecules to initiate the cell-death cascade.

Considering symptom induction by native ToxA (Fig. 2A, B, and $\mathrm{C}$ ), as the concentration of infiltrated ToxA is decreased (from 0.5 to $0.004 \mu \mathrm{M}$ ), the severity and time course of symptom development remain approximately the same but the size of the lesion shrinks dramatically (Tuori et al. 1995). As we have noted previously (Manning and Ciuffetti 2005), this implies the presence of a high-affinity receptor that strongly limits the spread of ToxA molecules during infiltration. The sharp transition between severely necrotic and unaffected tissue (Fig. $2 \mathrm{D}$, top leaf) further supports this conclusion because it indicates a sharp concentration gradient at that point. Because the time course of symptom development in the necrotic region is similar for all concentrations tested (i.e., maximum size or severity for each treatment generally is achieved by day 3), we infer that the ToxA-binding sites are being nearly saturated in the necrotic areas of all infiltrations, even at $0.004 \mu \mathrm{M}$ (i.e., 4 $\mathrm{nM})$. If, at $4 \mathrm{nM}$ of ToxA, the ToxA binding sites are $\geq 80 \%$ saturated, then the upper limit for the effective $\mathrm{Kd}$ of the ToxA:ToxA binding site interaction is $1 \mathrm{nM}$ (see Methods). Furthermore, because the size of the symptom that develops depends on the amount of ToxA infiltrated, we can estimate the number of apparent ToxA binding sites present (Table 1). The estimates calculated for each concentration $(0.5,0.1,0.02$, and $0.004 \mu \mathrm{M}$ ) are approximately $3 \times 10^{6}$ ToxA binding sites per cell and are remarkably similar given the approximations involved in the calculation.
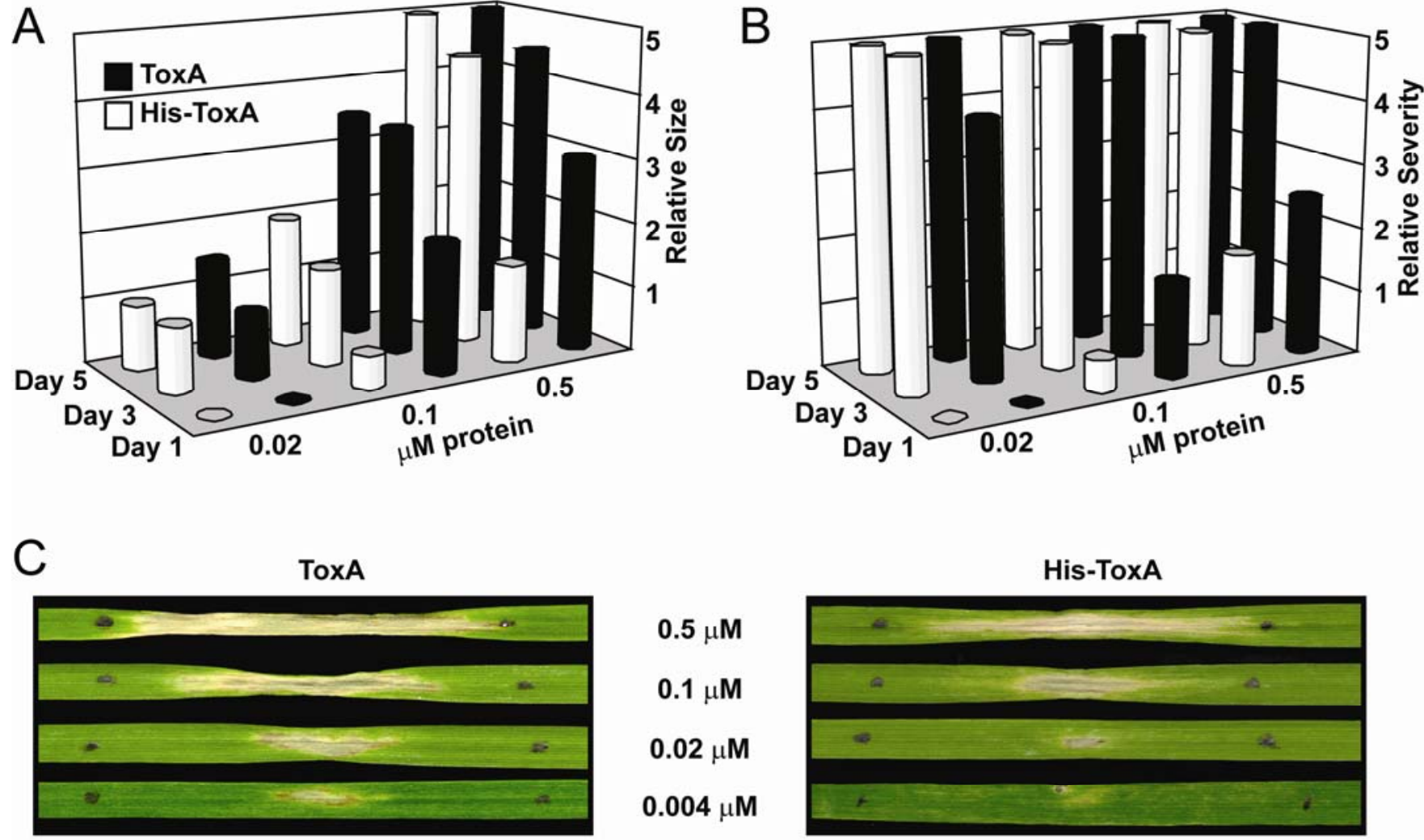

\section{$0.5 \mu \mathrm{M}$ \\ $0.1 \mu \mathrm{M}$ \\ $0.02 \mu \mathrm{M}$ \\ $0.004 \mu \mathrm{M}$}
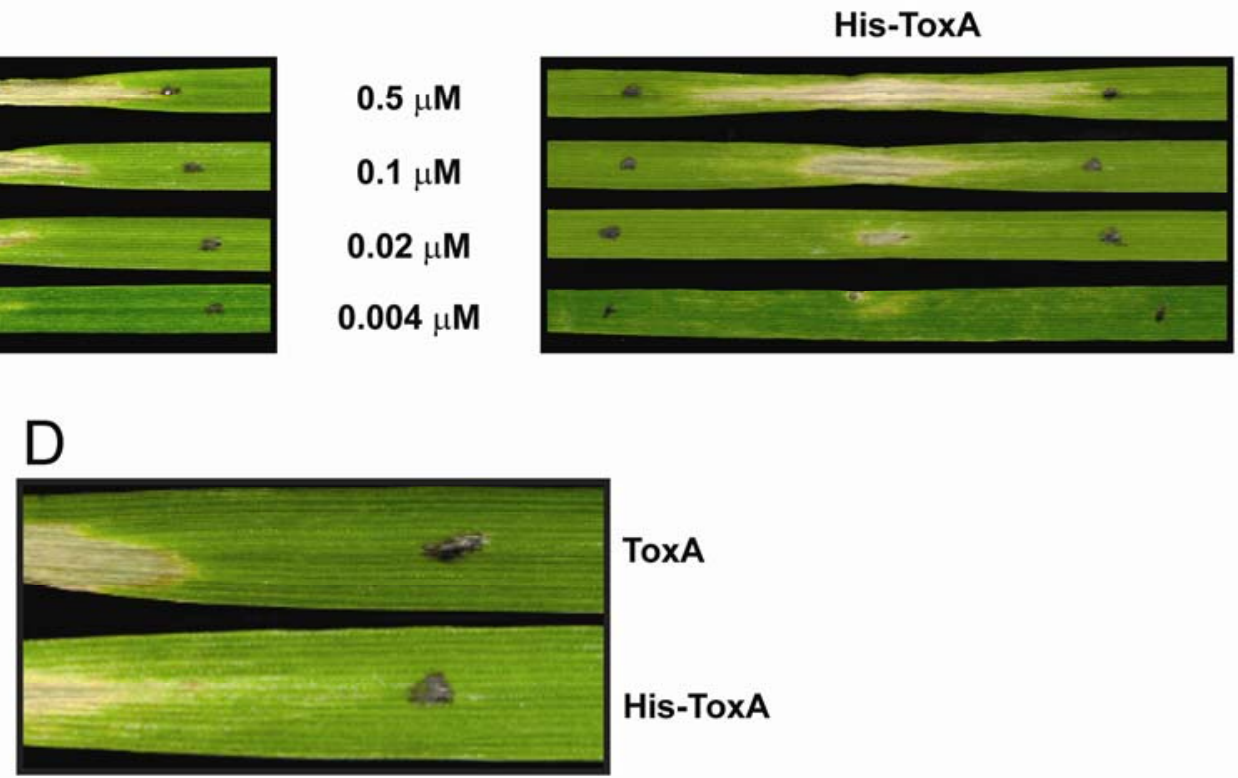

Fig. 2. Comparison of native ToxA and His-ToxA activity. A, Relative size and $\mathbf{B}$, severity of symptoms produced by different concentrations of toxin over time. C, Bioassay of decreasing concentrations of toxin. D, Enlargement of leaves infiltrated with $0.1 \mu \mathrm{M}$ toxin. Dots demarcate treatment zone. Leaves were harvested at day 5 . 
Relative importance of individual residues in the solvent-exposed, RGD-containing loop.

Given that method 2 (Fig. 1A) produces more reliably folded protein, we next used the semiquantitative bioassay to reassess the activities of each of the ToxA variants with a mutation in the solvent-exposed, RGD-containing loop (residues 136 through 143) (Fig. 3A, box). In addition, we produced the E145A variant because of its altered mobility on SDS-PAGE in the previous analysis (Manning et al. 2004) and the T126A variant as a positive control mutant at a position outside of the loop that behaves similarly to His-ToxA when produced by method 1. Inspection of the crystal structure of ToxA suggests that $\mathrm{Xaa} \rightarrow$ Ala mutations at all of these sites would not affect the structure or stability of the protein (Sarma et al. 2005). Moreover, previous analyses of His-tagged proteins with mutations of each residue within the vitronectin-like domain (residues 137 to 147) (Fig. 3A, underline) showed that all of these variants, with the exception of V138A, had severely impaired activity (Manning et al. 2004; Meinhardt et al. 2002; Tuori et al. 2000). All mutant proteins produced by method 2 purify to a single band and migrate similarly on SDS-PAGE (Fig. 3B).

To determine the activity of these variants, semiquantitative bioassays were performed at 0.5 and $0.1 \mu \mathrm{M}$ for each ToxA variant. Infiltration of N136A, T139A, G141A, and D142E induce no symptom development even when infiltrated at a concentration of $2 \mu \mathrm{M}$ (data not shown) and as previously described (Manning et al. 2004). Other variants showed varying levels of activity (Fig 3C through F). Symptoms are visible at day 1 in leaves infiltrated with $0.5 \mu \mathrm{M}$ His-ToxA and mutant proteins T126A, V138A, and E145A (Fig. 3C and D). Especially interesting are mutations T126A and V138A, for which the relative size of the symptom is much larger than that of His-ToxA at day 1. By day 5, both the relative size (Fig. 3C) and severity (Fig. 3D) of symptoms induced by T126A and V138A are comparable to His-ToxA. This is in contrast to E145A, which induces a similar level of severity but whose relative size of leaf affected is less than half that of leaves treated with His-ToxA. R140A and V143A at $0.5 \mu \mathrm{M}$ elicit no symptoms at day 1 and do not induce the size or severity of symptoms as His-ToxA by day 5. T137A induces very low symptom development (Fig. 3C and D). When ToxA-sensitive leaves were infiltrated with $0.1 \mu \mathrm{M}$ protein, all mutant proteins tested at all time points were significantly less effective at inducing symptoms than His-ToxA (Fig. 3E and F). Given the above activity data based on the size and severity of symptom development, mutant proteins are placed into groups from most to least active: group $1=\mathrm{T} 126 \mathrm{~A}$ and V138A (most active); group 2 = T137A, R140A, V143A, and E145A; and group $3=$ N136A, T139A, G141A, and D142E (least active).

\section{Phosphorylation of the RGD loop is not required for ToxA activity.}

ToxA contains six potential phosphorylation sites (Ciuffetti et al. 1997; Zhang et al. 1997). Mutagenesis of two putative CKII-phosphorylation sites, T139 and T132, resulted in reduced ToxA activity, whereas mutagenesis of the other four sites had little effect (Manning et al. 2004). In the crystal structure of ToxA (Sarma et al. 2005), the side chain of T139 is fully accessible for phosphorylation and that of T132 is partially exposed; thus, their importance for activity may reflect a required phosphorylation event in planta (Sarma et al. 2005). Therefore, we utilized two assays to determine whether phosphorylation of ToxA can occur in planta.

In vitro kinase assays were performed with lysates from ToxA-treated (induced) and untreated leaves with His-ToxA as a substrate (Fig. 4A). Induced lysates were included in the event that ToxA treatment was required for the activity of the kinase responsible for phosphorylation. Both induced and untreated lysates, either with His-ToxA or without (control), have a phosphorylated band that migrates at $16 \mathrm{kDa}$ (Fig. 4A, panels a and b). When His-ToxA is included as a substrate, neither lysate phosphorylates a protein that corresponds to His-ToxA (Fig. 4A; compare panels $b$ and c). That His-ToxA is not degraded or modified during the kinase assay was confirmed by a Western blot with ToxA antiserum (Fig. 4A, panel c). Additionally, purified CKII did not phosphorylate His-ToxA in vitro (data not shown).

To determine whether ToxA is phosphorylated on threonines in vivo, sensitive wheat leaves were treated with His-ToxA and, at various times after treatment, His-ToxA was reisolated and assessed by Western blot analysis for threonine phosphorylation. Analysis of wheat whole-leaf extracts showed that the antiphosphothreonine antibody detects several phosphorylated proteins (Fig. 4B, right panel). However, the antibody did not recognize His-ToxA reisolated from treated plants up to $8 \mathrm{~h}$ following infiltration (Fig. 4B, top panel). Reisolation of HisToxA from treated leaves was confirmed by reprobing the same blot with ToxA antiserum (Fig. 4B, bottom panel).

\section{The solvent-exposed, RGD-containing loop of ToxA is required for internalization.}

It has been shown that ToxA is internalized into mesophyll cells of ToxA-sensitive wheat leaves (Manning and Ciuffetti 2005) and that the RGD-containing loop is important for activity (Manning et al. 2004; Meinhardt et al. 2002); however, it is not known whether the RGD-containing loop is important for internalization or another step involved in toxicity. To address this, we tested whether the peptide RGDV that strongly inhibits ToxA activity (Manning et al. 2004) also blocks internaliza-

Table 1. Estimation of the number of high-affinity native ToxA binding sites per cell

\begin{tabular}{|c|c|c|c|c|c|}
\hline$\overline{\operatorname{Tox} A}(\mu \mathbf{M})^{\mathbf{a}}$ & Molecules of ToxA $A^{b}$ & Leaf area $\left(\mathrm{cm}^{2}\right)^{\mathrm{c}}$ & Leaf cells $^{d}$ & Fraction area necrotic ${ }^{\mathrm{e}}$ & No. of receptors/cell ${ }^{f}$ \\
\hline 0.5 & $3,000 \times 10^{9}$ & 1.28 & $1.60 \times 10^{5}$ & 0.85 & $3.3 \times 10^{6}$ \\
\hline 0.1 & $600 \times 10^{9}$ & 1.47 & $1.84 \times 10^{5}$ & 0.50 & $3.3 \times 10^{6}$ \\
\hline 0.02 & $120 \times 10^{9}$ & 1.71 & $2.14 \times 10^{5}$ & 0.15 & $3.2 \times 10^{6}$ \\
\hline 0.004 & $24 \times 10^{9}$ & 1.67 & $2.09 \times 10^{5}$ & 0.04 & $2.8 \times 10^{6}$ \\
\hline
\end{tabular}

a ToxA concentrations are based on BCA assays (Pierce) and are expected to be within $20 \%$ of the true protein concentration (see manufacturer's instructions).

${ }^{\mathrm{b}}$ Exact infiltration volumes are not recorded, but are typically $10 \pm 2 \mu \mathrm{l}$; therefore, $10 \mu \mathrm{l}$ is used for this calculation.

c Areas are the length of the infiltration zone multiplied by the average of the leaf widths at each end of the zone.

${ }^{\mathrm{d}}$ Number of cells is based on a $1.25 \times 10^{5}$ cells $/ \mathrm{cm}^{2}$ relationship derived for second leaves of Triticum aestivum from research by Pyke and associates (1990). We estimate this to be $\pm 10 \%$.

e For this estimate, two photocopies at fourfold linear magnification were made from the bioassay of leaves with decreasing concentrations of toxin. For one set, the leaf area corresponding to the complete infiltration zone was cut out and weighed and, for the other set, the area that was strongly necrotic was cut out and weighed. The fraction reported is the ratio of these two weights rounded off to the nearest 0.05 or to one significant figure. We estimate this is accurate to within $10 \%$.

${ }^{f}$ The number $(N)$ of receptors per cell is calculated by the equation $N=\left(\left[1-f_{n}\right] \times M\right) /\left(f_{n} \times C\right)$, where $f_{n}$ is the fraction necrotic tissue, $M$ is the number of ToxA molecules, and $\mathrm{C}$ is the number of cells in the infiltration zone. 
tion, and whether RGD mutant proteins with impaired activity (Manning et al. 2004; Meinhardt et al. 2002) also have impaired internalization. For both of these studies, the protease protection assay previously developed was utilized (Manning and Ciuffetti 2005).

For peptide studies, ToxA-sensitive leaves were treated with His-ToxA, His-ToxA+RGDV, or His-ToxA+RGES, where the RGES is a control peptide that slightly inhibits ToxA activity in a non-dose-dependant manner (Manning et al. 2004). After $2 \mathrm{~h}$, extracellular ToxA was degraded by treatment with pro- teinase $\mathrm{K}(\mathrm{PK})$. His-ToxA that had been internalized and, therefore, protected from protease treatment was purified and detected via Western blot analysis with ToxA antiserum. Detectable amounts of His-ToxA are internalized in His-ToxAtreated and His-ToxA+RGES-treated cells but not in HisToxA+RGDV-treated cells (Fig. 5A). This suggests that the inhibition of ToxA activity by the RGDV peptide is due to a decrease in ToxA internalization.

To more directly assess whether the RGD-containing loop is important for internalization, the protease protection assay was
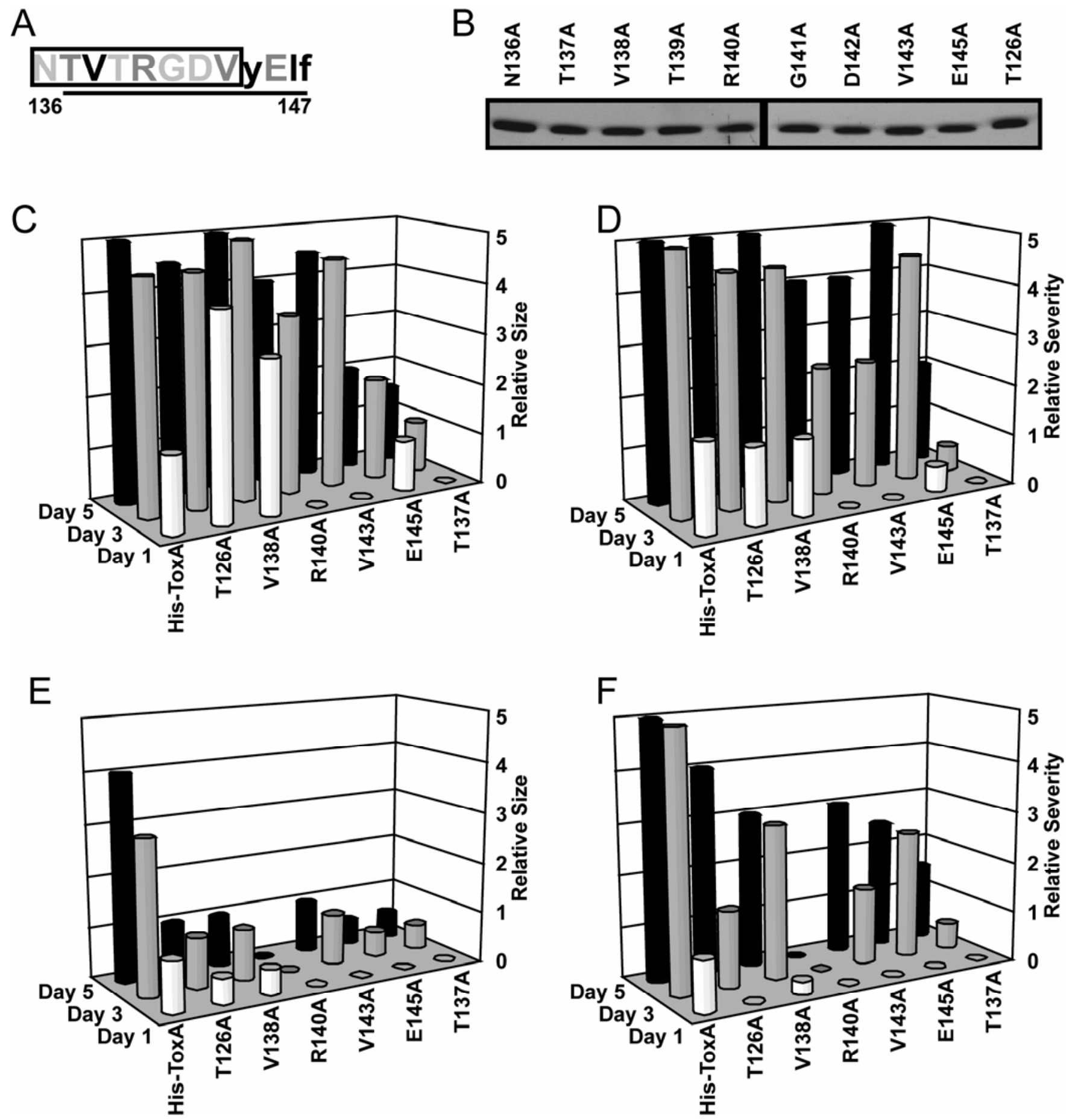

Fig. 3. Activity of His-ToxA mutant proteins. A, Schematic of the solvent exposed, RGD-containing loop (box) and vitronectin-like sequence (underline) of ToxA. Amino acids are shaded from black to light gray depending upon how Xaa to Ala mutagenesis affects activity. Slight affect is shown in black, intermediate in gray, and complete loss of activity in light gray. Amino acids of the vitronectin-like loop that were not tested are indicated in lowercase. B, Silver stained sodium dodecyl sulfate polyacrylamide gel electrophoresis of $1 \mu \mathrm{g}$ of heterologously expressed protein. C, Relative size and $\mathbf{D}$, severity of symptoms induced by treatment with $0.5 \mu \mathrm{M}$ protein. $\mathbf{E}$, Relative size and $\mathbf{F}$, severity of symptoms induced by treatment with $0.1 \mu \mathrm{M}$ protein. 
performed with His-ToxA and three His-ToxA variants with a mutation in the loop, one from each of the activity groups described above: V138A from group 1, V143A from group 2, and $\mathrm{D} 142 \mathrm{E}$ from group 3. Protein was recovered from leaves treated with protein alone (representing extracellular and intracellular protein) (Fig. 5B, odd lanes) or protein followed by PK-treatment $2 \mathrm{~h}$ post toxin infiltration (representing protein protected by internalization) (Fig. 5B, even lanes). Consistent
A

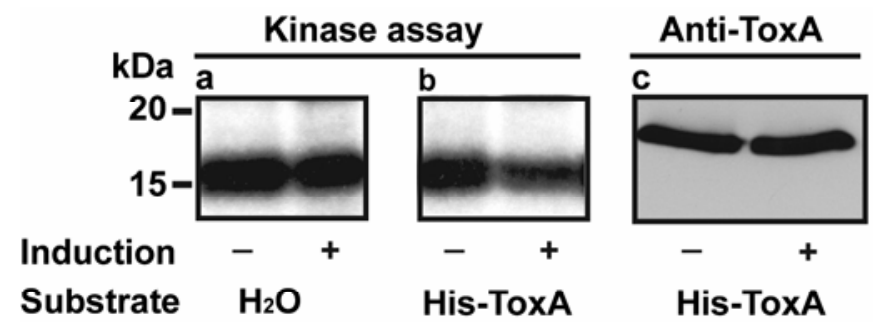

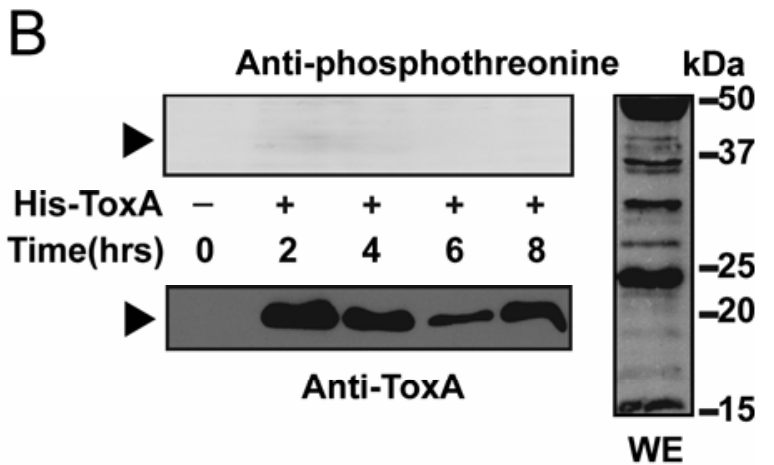

Fig. 4. His-ToxA is not phosphorylated in vitro or in vivo. A, In vitro kinase assay with lysates from ToxA-treated or -untreated (induced + or - , respectively) leaves. In vitro kinase reaction substrate: $\mathrm{a}, \mathrm{H}_{2} \mathrm{O}$ and b, His-ToxA; c, Western blot analysis with ToxA antiserum of His-ToxA purified from in vitro kinase assay. Migration of molecular mass markers $(\mathrm{kDa})$ indicated on the left. B, Assay for in vivo phosphorylation of His-ToxA. Western blot analysis with an anti-phosphothreonine antibody of His-ToxA purified from leaves at indicated times after toxin treatment (top panel). The same blot in the top panel probed with ToxA anti-serum (bottom panel). Western blot analysis of wheat leaf total protein extract (WE) with an anti-phosphothreonine antibody (right panel). Arrow indicates the position of His-ToxA migration.

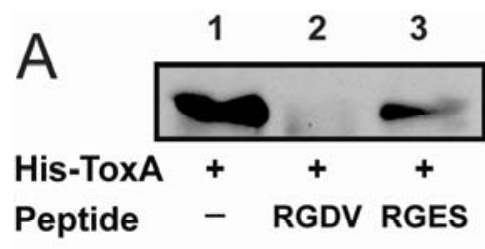

B

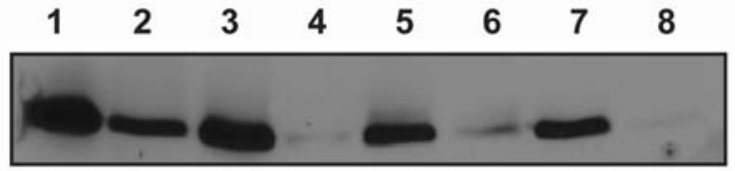

PK

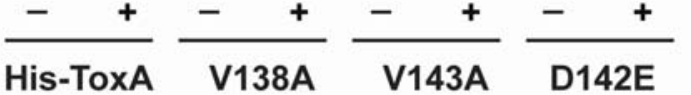

D

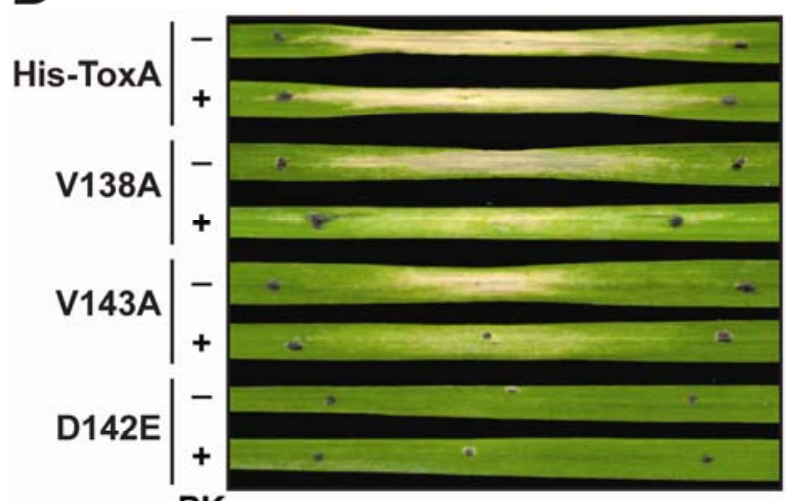

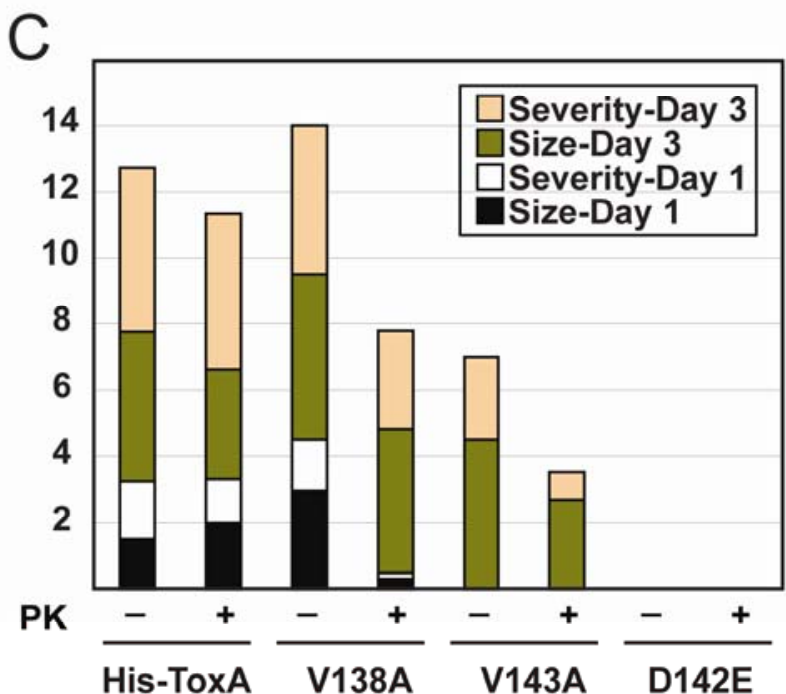

$E$

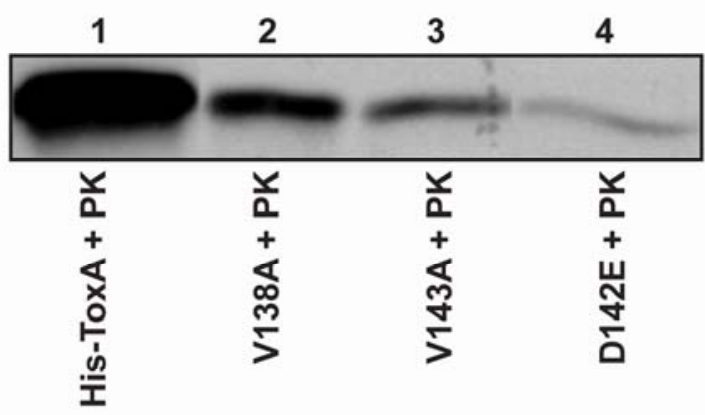

Fig. 5. Internalization of His-ToxA proteins requires the solvent-exposed loop. A, Western blot analysis of His-ToxA isolated from leaves treated with lane 1, HisToxA alone; lane 2, His-ToxA + RGDV-peptide; or lane 3, His-ToxA + RGES- peptide for $2 \mathrm{~h}$ followed by treatment with proteinase K (PK). B, Western blot analysis of His-ToxA variants isolated from leaves with $(+)$ or without (-) PK treatment $2 \mathrm{~h}$ post toxin treatment. C, Comparison of the size and severity of symptom development induced by $0.5 \mu \mathrm{M}$ His-ToxA variant \pm PK treatment $2 \mathrm{~h}$ post toxin treatment. Each bar represents combined data collected on day 1 and day 3. Graph is the average of three experiments. D, Day 5 leaves treated as described in C. Dots demarcate treatment zone. E, Western blot analysis of His-ToxA variants isolated from leaves treated with protein followed by PK treatment $10 \mathrm{~h}$ post toxin treatment. 
with our previous work (Manning and Ciuffetti 2005), a significant amount of His-ToxA is protected at the 2-h time point (Fig. 5B; compare lanes 1 and 2). His-ToxA and mutant proteins can be detected in leaves that have not been treated with PK (Fig. 5B, lanes 1, 3, 5, and 7), whereas little detectable protein is seen for any of the mutants after PK treatment (Fig. 5B, lanes 4, 6, and 8). This was not expected, because both V138A and V143A induce symptoms.

To test the hypothesis that V138A and V143A require more time than His-ToxA to be internalized, plants were treated with PK $2 \mathrm{~h}$ post toxin treatment and symptom development (relative size and severity) was monitored over 5 days (Fig. 5C and D). Leaves treated with His-ToxA \pm PK developed symptoms similarly over the course of the bioassay. Leaves treated with V138A + PK versus V138A alone exhibited strongly reduced size and severity of symptom development at day one. Although the size of the symptom was similar in both treatments on day 3 and day 5, the severity was decreased in PK-treated leaves (Fig. 5C and D). Similarly, for V143A, the observed severity of symptoms on days 3 and 5 was reduced in PK-treated leaves (Fig. 5C and D). As expected, D142E produced no symptoms with or without PK treatment (Fig. 5C and D). These data support the hypothesis that the uptake of V138A and V143A differs from His-ToxA.

Given this information, the PK protection assay was repeated with a 10-h delay before PK treatment, extending the time allowed for toxin uptake. Under these conditions, V138A and V143A were protected at significant levels that correlate with their activity (Fig. 5E). A trace amount of D142E was also detectable, but this most likely does not reflect internalization of D142E but, rather, the inability to infiltrate the exact same area of the leaf with both toxin and then PK $10 \mathrm{~h}$ later. In other words, some toxin may escape treatment with protease.

\section{DISCUSSION}

The studies presented in this work advance our understanding of the structure-function relationships for Ptr ToxA. The insights were made possible by an improved method (method 2) for refolding His-ToxA variants heterologously expressed in E. coli and expansion of the amount of information gleaned from the leaf infiltration bioassay. It has been observed that proper protein refolding from solubilized inclusion bodies can be inhibited by the presence of aggregates and impurities found in inclusion bodies (Tsumoto et al. 2003); therefore, we altered our purification protocol to perform nickel chromatography prior to rather than after refolding (Fig. 1). Two lines of evidence that indicate method 2 is an improvement over method 1 are i) the E145A mutant protein migrated differently than His-ToxA on an SDS-PAGE gel when produced by method 1 (Manning et al. 2004) but similarly when produced by method 2 (Fig. 4B) and ii) four ToxA variants (T137A, R140A, V143A, and E145A) that had no activity when produced by method 1 showed some activity, albeit still reduced in comparison with His-ToxA, when produced by method 2 (Fig. 3). In addition, a newly developed semiquantitative bioassay allows us to document the effect of a given ToxA concentration or ToxA variant on multiple parameters: i) the time course of symptom development, ii) the size of the affected region, and iii) the severity of necrosis.

\section{Comparison of the activity of native ToxA with heterologously expressed His-ToxA variants.}

His-ToxA has similar activity to native ToxA (Fig. 2). HisToxA, like ToxA, displays high-affinity binding, as indicated by the decreasing size of the symptom with decreasing amounts of protein and by the severity of the symptom. The slight decrease in activity may reflect a slight decrease in affinity of these proteins for receptor or low levels of imperfectly folded molecules that have lower affinity and spread further into the treatment zone (Fig. 2D).

That His-ToxA has near-wild-type activity allows the mutants to be used to establish how the individual amino acids within the RGD-containing, solvent-exposed loop contribute to ToxA activity (Fig. 3C, D, E, and F). Taken together, these results show that all mutants are impaired and can be organized roughly into three groups according to importance for activity (Fig. 3A). Group 1 mutants (V138A and T126A) have a relatively minor loss in activity, behaving similarly to His-ToxA at $0.5 \mu \mathrm{M}$ but showing distinctly lower activity at $0.1 \mu \mathrm{M}$ (Fig. 3C, D, E, and F). Next, group 2 mutants (T137A, R140A, V143A, and E145A) have markedly reduced activity even at $0.5 \mu \mathrm{M}$, but not complete loss of activity (Fig. 3C, D, E, and F). Finally, group 3 mutants (N136A, T139A, G141A, and D142E) show no toxic activity even at the highest concentration tested. Because T139 is a putative CKII-phosphorylation site and because T139A shows impaired activity, we tested whether it becomes phosphorylated. We were unable to detect phosphorylation of His-ToxA either in vivo or in vitro (Fig. 4). Therefore, it appears that T139 in ToxA does not function as a target for a kinase. Although group 2 mutants show more activity than our previous report indicated (Manning et al. 2004), the conclusion remains the same that Ala mutations at all RGD-loop positions except for V138 markedly impair activity. It is worth noting that the $\mathrm{Val} \rightarrow$ Ala mutation is fairly conservative and, therefore, may not reflect the true importance of V138 for ToxA activity.

The semiquantitative assay allows us to gain insights into the mechanism by which the activity of ToxA is impaired. For the group 3 mutants, showing no activity at any tested concentration, nothing can be learned based on this assay about what step in the process is impaired. However, for the partially active mutants, we are able to conclude that the group 1 mutants V138A and T126A both have decreased affinity for a postulated receptor because, when these proteins are infiltrated at $0.5 \mu \mathrm{M}$, the relative size, but not severity, of symptom development at day 1 is larger than that induced by His-ToxA (Fig. 3C). Lower affinity for a receptor would lead to protein spreading further into the treatment zone from the point of infiltration, unlike the high-affinity interaction of His-ToxA and a receptor, and account for the larger area displaying symptoms. The utility of varying toxin concentration in the assay is powerfully illustrated by these variants. Based on the $0.5 \mu \mathrm{M}$ infiltrations, it appears that these mutants are more active than HisToxA; however, the $0.1 \mu \mathrm{M}$ infiltrations show that this is not the case (Fig. 3C, D, E, and F). This underscores the importance of testing nonsaturating amounts of toxin when assessing toxic activities. Unlike V138A and T126A, E145A appears to bind tightly to a receptor because the size of the symptom on day 1 is similar to His-ToxA (Fig. 3A); however, the symptoms never completely fill the infiltration zone. Additionally, internalization of E145A is impaired (data not shown). Therefore, it is possible that E145A represents a variant that has the ability to bind to a receptor similarly to His-ToxA, is internalized at a slower rate, and, once internalized, may be less able to induce necrosis.

The semiquantitative assay also provides a framework for understanding how the amount of toxin internalized correlates with the onset of necrosis. For example, by monitoring symptom development induced by ToxA over time, we find that the size of the area affected increases (Fig. 2A). Therefore, necrosis occurs rapidly in areas where the concentration of toxin is the greatest and develops more slowly in the areas where a lesser concentration of toxin is available. 


\section{The RGD-containing, solvent-exposed loop is required for internalization.}

The bioassay itself cannot distinguish to what extent impaired ToxA variants are defective in internalization as opposed to being defective at triggering cell death once internalized. To answer this question, we assessed toxin internalization by adapting our previously published PK protection assay. As previously demonstrated (Manning and Ciuffetti 2005), HisToxA-induced symptom development is similar with or without $2 \mathrm{~h}$ of PK treatment (Fig. 5C and D), indicating that relevant internalization is complete by the 2-h time point. Surprisingly, little V138A is protected at $2 \mathrm{~h}$ (Fig. 5B) and symptom development in leaves treated with V138A for $2 \mathrm{~h}$ followed by PK treatment is delayed and diminished when compared with V138A alone (Fig. 5C and D). These results indicate that significant internalization of V138A must occur after the $2 \mathrm{~h}$ time point. By extending the PK protection assays to $10 \mathrm{~h}$, we were able to show that significant levels of V138A are internalized. At that time, the amount of internalized protein is HisToxA $>$ V138A $>$ V143A $>>$ D142E (Fig. 5E). This corresponds well with the relative activities of these mutant proteins (Fig. $5 \mathrm{C}$ and $\mathrm{D}$ ), supporting the conclusion that the amount of toxin internalized correlates with disease.

Additional support for this conclusion comes from the RGD peptide competition experiments. Co-treatment of His-ToxA with RGDV peptide results in the reduction of both ToxA activity in a dose-dependant manner (Manning et al. 2004) and the amount of His-ToxA that is internalized (Fig. 5A). Because the impairment of activity of RGD loop mutants correlates with impaired internalization, and the reduction of activity by RGDV peptide co-treatment also is correlated with impaired internalization, we conclude that the RGD-containing, solventexposed loop in ToxA is critical for receptor recognition and internalization.

\section{RGD-receptors and protein import into plant cells.}

The RGD cell-attachment motif has been shown to be important in extracellular matrix-plasma membrane interactions in animal systems and cell wall-plasma membrane interactions in plants (Baluska et al. 2003). Although RGD peptide inhibition of activity (Manning et al. 2004; Meinhardt et al. 2002) and internalization (Fig. 5) confirm the importance of the RGD cell attachment motif for ToxA activity, decreased activity and internalization of proteins that contain mutations of other residues of the RGD-containing loop suggest a situation that is more complex. Recently, a plasma membrane-localized lectin receptor kinase (LecRK, At5g60300) in Arabidopsis was shown to interact with an RGD-containing protein from Phytophthora infestans, IPI-O, and this interaction could be inhibited by the addition of RGD-containing peptides (Gouget et al. 2006). It is possible that ToxA, through the RGD-containing, solvent-exposed loop, interacts with a similar protein on wheat mesophyll cells.

The number of estimated binding sites for ToxA in sensitive cells is $3 \times 10^{6} /$ cell (Table 1 ), which is within the range of estimates of high-affinity binding sites of other molecules produced by plant pathogens (Dubery and Meyer 1995; Nurnberger et al. 1994) and similar to the number of Harpin binding sites present on tobacco protoplasts (Lee et al. 2001). The Kd for the interaction with ToxA and these binding sites is estimated at $\leq 1$ $\mathrm{nM}$, which is in line with a high-affinity interaction. The strength of the interaction between ToxA and its high-affinity binding site and the number of these sites present on plant cells is likely to determine differential plant responses. Lower binding affinity or lower numbers of receptors on the plant cell surface mean fewer molecules of toxin can bind and be internalized, resulting in a reduction of necrotic symptom develop- ment. In the struggle for the upper hand in the plant-pathogen interaction, a single amino acid change in toxin or binding site could have serious implications. In fact, it has been shown that a single amino acid change in the plant $\mathrm{R}$ protein, Pi-ta, is enough to determine whether plants will be susceptible or resistant to Magnaporthe oryzae expressing Avr-Pita (Bryan et al. 2000).

Given the importance of the RGD-containing loop in internalization (Fig. 5), the presence of a high-affinity binding site on ToxA-sensitive cells (Table 1), and the shared characteristics of ToxA-induced symptom development with receptormediated endocytosis (Manning and Ciuffetti 2005), our working model is that ToxA binds to a high-affinity receptor via the RGD-containing loop. After binding, ToxA is internalized by receptor-mediated endocytosis into the endosomal compartment of the plant cell. Here, it dissociates from the receptor, escapes the endosome, and enters the cytosol. Finally, ToxA is targeted to the chloroplast, which is the ultimate site of action (Fig. 6). In plants, receptor endocytosis can occur in the absence of ligand, as is the case for the brassinosteroid receptor BRI1 (Russinova et al. 2004), or in response to ligand, as recently reported for the flagellin receptor FLS2 (Robatzek et al. 2006). Following internalization, receptors can be found in endosomal compartments where they are either sorted for recycling to the membrane or sent to the vacuole for degradation (Geldner and Jurgens 2006; Murphy et al. 2005; Samaj et al. 2005). As previously reported (Manning and Ciuffetti 2005), both ToxA-immunolocalization and green fluorescent proteinToxA localization indicate that ToxA is present in a cytosolic compartment that could represent an endosome (Fig. 6A, open triangles) and also associates with the chloroplast (Fig. 6B, closed triangles). Studies are underway to confirm our working model.

The protein or proteins with which ToxA interacts at the cell membrane are not yet identified; however, knowing that the RGD loop is required for internalization is an important step in identifying this protein. Interestingly, although much of what occurs once ToxA is internalized is still unknown, there is evidence that the same solvent-exposed loop also could be important for interactions with intracellular proteins. Specifically, ToxABP1, a chloroplast protein that interacts with ToxA, can interact with ToxA mutated in the RGD sequence but not with ToxA mutated at T137, an amino acid upstream of the RGD sequence but within the vitronectin-like loop (Manning et al. 2007). Development of a method for assessing the function of ToxA mutant proteins within plant cells while bypassing the need for internalization is currently underway in our laboratory and promises to shed further light on residues important for the intracellular interactions of ToxA.

\section{MATERIALS AND METHODS}

\section{Preparation of proteins.}

Native ToxA was produced as described by Tuori and associates (1995). Plasmids used for expression of recombinant His-tagged ToxA fusion proteins were described previously (Manning et al. 2004). Cultures (6 ml) were grown overnight in Luria-Bertani (LB) (10 g of tryptone, $5 \mathrm{~g}$ of $\mathrm{NaCl}$, and $5 \mathrm{~g}$ of yeast extract/liter) plus ampicillin at $100 \mu \mathrm{g} / \mathrm{ml}$. Two $250-$ $\mathrm{ml} \mathrm{LB}$ cultures each were inoculated with $2.5 \mathrm{ml}$ of the overnight culture and grown at $37^{\circ} \mathrm{C}$ with shaking for $1 \mathrm{~h}$. Protein expression was induced by the addition of $250 \mu \mathrm{l}$ of $0.1 \mathrm{M}$ isopropyl- $\beta$-D-thiogalactopyranoside to each culture, and induction continued for $4 \mathrm{~h}$ at $30^{\circ} \mathrm{C}$ with shaking. Cells were harvested via centrifugation at $6,000 \times g$ for $10 \mathrm{~min}$ and each pellet was lysed in $4 \mathrm{ml}$ of $1 \times$ BugBuster (Novagen, EMD Biosciences, Inc., La Jolla, CA, U.S.A.). Lysates were transferred to 
Oakridge tubes and $4 \mu \mathrm{l}$ of Benzonase (Novagen) was added to the lysate and mixed for 5 to $10 \mathrm{~min}$ at room temperature. Inclusion bodies were harvested by centrifugation at $16,000 \times g$ and $4^{\circ} \mathrm{C}$ for $20 \mathrm{~min}$. Inclusion bodies were washed $1 \times$ with 2.5 $\mathrm{ml}$ of $1 \times$ BugBuster and repelleted. Isolation of His-tagged proteins was performed using the His-bind kit (Novagen) following the manufacturer's instructions for purifying protein under denaturing conditions. Briefly, $2 \mathrm{ml}$ of His-bind resin was loaded into an empty 2-ml column and allowed to pack via gravity flow. The column was washed with $3 \mathrm{ml}$ of doubledistilled $\mathrm{H}_{2} \mathrm{O}, 5 \mathrm{ml}$ of $1 \times$ charge buffer, and $3 \mathrm{ml}$ of $1 \times$ binding buffer with $6 \mathrm{M}$ guanidinium. Inclusion body pellets were resuspended in $2.5 \mathrm{ml}$ of $1 \times$ binding buffer with $6 \mathrm{M}$ guanidinium and added to column, and the column was eluted by gravity feed. The column was washed with $10 \mathrm{ml}$ of $1 \times$ binding buffer with $6 \mathrm{M}$ guanidinium followed by $6 \mathrm{ml}$ of $1 \times$ wash buffer with $6 \mathrm{M}$ guanidinium and eluted into a sterile $15-\mathrm{ml}$ conical tube with $6 \mathrm{ml}$ of $2 \times$ elution buffer with $4 \mathrm{M}$ guanidinium. Proteins were refolded as previously described (Manning et al. 2004; Tuori et al. 2000). Final dialysis was performed two times against Epure water (Barnstead International, Dubuque, IA, U.S.A.). Proteins were quantified with the Pierce BCA protein assay kit (Pierce, Rockford, IL, U.S.A.) using RNAse A (R-5503; Sigma-Aldrich, St. Louis) as a standard. After quantification, $1 \mu \mathrm{g}$ of protein was resolved on a $13 \%$ SDSPAGE gel using the method of Fling and Gregorson (1986).

\section{Bioassays.}

Three secondary leaves of the ToxA-sensitive cv. Katepwa were infiltrated with toxin (native ToxA, His-ToxA, and mutant His-ToxA proteins.) Leaves were monitored each day for symptom severity and the percent of the infiltrated zone affected. After 5 days, leaves were harvested and scanned on a flatbed scanner (Epson, Long Beach, CA, U.S.A.). As is common for bioassays, obtaining reliable quantitation was complicated by variation among individual leaves and by the subjective nature of the scoring of size and severity. To minimize the influence of these complexities, all reported scores are the average of the results for three leaves scored by direct side-by-side comparison with the image shown in Supplemental Figure 1. Therefore, the results of these assays are semiquantitative rather than quantitative; they are useful for assessing clear, broad trends but not for assigning significance to minor deviations.

Each His-tagged protein was produced at least two times and each was tested at least two times to ensure similar results. Graphs comparing symptom size and severity are an average of two independent experiments using two different preparations of the mutant proteins. Day 5 leaves shown in figures are representative of typical leaves.

\section{Estimates of apparent receptor affinity and number.}

Because the ToxA receptor is assumed to be membrane bound rather than freely soluble, the binding event involves a twophase system and treatment as a soluble system is not technically justified. Nevertheless, an estimate of the apparent or effective $\mathrm{Kd}$ can be derived by treating the reaction as an equilibrium between soluble components. Using Tox $\mathrm{A}_{\text {free }}$ to designate ToxA remaining unbound, $\mathrm{R}_{\text {free }}$ for the unliganded receptor, $\mathrm{R}_{\text {bound }}$ for the receptor:ToxA complex, and $\mathrm{R}_{\text {total }}$ for the total receptor present (i.e., $R_{\text {total }}=R_{\text {free }}+R_{\text {bound }}$ ), it is possible to formulate $\mathrm{Kd}$ in terms of the fractions of free and bound receptor:

$\mathrm{Kd}=\left(\left[\right.\right.$ Tox $\left.\left.\mathrm{A}_{\text {free }}\right] \times\left[\mathrm{R}_{\text {free }}\right]\right) / \mathrm{R}_{\text {bound }}=$ Tox $\mathrm{A}_{\text {free }} \times\left(\mathrm{R}_{\text {free }} /\left(\mathrm{R}_{\text {total }}\right) \times\right.$ $\left(\mathrm{R}_{\text {total }} / \mathrm{R}_{\text {bound }}\right)=$ Tox $_{\text {free }} \times$ fraction $_{\text {free }} /$ fraction $_{\text {bound }}$

Assuming the receptor is $80 \%$ saturated (i.e., $20 \%$ free) for the $4 \mathrm{nM}$ infiltration (i.e., $\operatorname{Tox}_{\text {free }}=4 \mathrm{nM}$ ) then $\mathrm{Kd}=4 \mathrm{nM} \times$ $(0.2 / 0.8)=1 \mathrm{nM}$. If the saturation is higher, then the $\mathrm{Kd}$ is lower.
An estimate for the number of ToxA molecules bound to high-affinity binding sites per cell can be made by noting the total number of ToxA molecules infiltrated (M) and considering that, if no high-affinity receptors existed, the ToxA molecules would be evenly spread throughout the infiltration zone. Because the infiltrated solution becomes depleted of ToxA when ToxA binds, the fraction of the infiltration zone depleted of ToxA must be an indication of the number of ToxA molecules bound. Using $\left(f_{n}\right)$ for the fraction of the leaf that is necrotic, $\left(1-f_{n}\right) \times M$ gives the number of ToxA molecules bound to high-affinity binding sites. Then, by assuming that binding occurs in the necrotic region, the number of cells binding these ToxA molecules is given by $f_{n} \times C$, where $C$ is the number of cells in the whole infiltration region. Thus, the number of ToxA molecules bound per cell is calculated by:

$$
\mathrm{N}=\left(\left[1-\mathrm{f}_{\mathrm{n}}\right] \times \mathrm{M}\right) /\left(\mathrm{f}_{\mathrm{n}} \times \mathrm{C}\right)
$$

\section{In vitro phosphorylation assay.}

Assays were performed similarly to those described by Suzuki and associates (1999). Briefly, three Katepwa leaves were infiltrated with $0.5 \mu \mathrm{M}$ native ToxA or $\mathrm{H}_{2} \mathrm{O}$ for $4 \mathrm{~h}$. The three infiltrated leaves were harvested and $3-\mathrm{cm}$ sections from the infiltration zone were combined, weighed, ground in liquid nitrogen, resuspended in 10 volumes (wt/vol) of buffer (10 $\mathrm{mM}$ Tris, $\mathrm{pH} 8.0 ; 1 \mathrm{mM} \mathrm{MgCl} 2$; and 1:100 HALT phosphatase inhibitors) (Pierce), centrifuged at $5,000 \times g$ at $4^{\circ} \mathrm{C}$, brought to $20 \%$ glycerol, and stored at $-20^{\circ} \mathrm{C}$. The assay was performed in $25 \mu \mathrm{l}$ consisting of $12.5 \mu \mathrm{l}$ of $2 \times$ kinase buffer $(20 \mathrm{mM}$ Tris, $\mathrm{pH}$ 8.0; $20 \mathrm{mM} \mathrm{MgCl}$; and $4 \mathrm{mM} \mathrm{MnCl}_{2}$ ), 1:100 HALT phosphatase inhibitors, $1 \mu \mathrm{g}$ of His-ToxA or $\mathrm{H}_{2} \mathrm{O}, 1 \mu \mathrm{l}$ of gammadATP32, and $5 \mu$ of lysate for $30 \mathrm{~min}$ at RT. Reactions were diluted with $500 \mu \mathrm{l}$ of wash buffer $(1 \times \mathrm{NiBB}[0.25 \mathrm{M} \mathrm{NaCl}$; $0.1 \mathrm{M} \mathrm{NaPO}_{4}, \mathrm{pH} \mathrm{8.0}$; and 4\% glycerol], $20 \mathrm{mM}$ imidazole, and $0.5 \%$ Tween-20), 1:100 HALT phosphatase inhibitors, and $20 \mu \mathrm{l}$ of Ni-NTA agarose beads (Qiagen, Valencia, CA, U.S.A.) and rotated at $4^{\circ} \mathrm{C}$ for $30 \mathrm{~min}$. Beads were washed $3 \times$ with wash buffer/1:100 HALT phosphatase inhibitors and eluted with $30 \mu \mathrm{l}$ of $1 \times$ NiBB per $500 \mathrm{mM}$ imidazole. Proteins were resolved on a $13 \%$ SDS-PAGE, the gel dried and exposed to X-ray film overnight at $-80^{\circ} \mathrm{C}$. Western blot analysis of pulled-down His-ToxA was performed as above but with no dATP. Proteins were blotted onto nitrocellulose (Osmonics Inc., Minnetonka, MN, U.S.A.) and a Western blot performed using a 1:5000 dilution of ToxA antiserum (Manning and Ciuffetti 2005) followed by a 1:80,000 dilution of anti-rabbit horseradish peroxidase (HRP)-conjugated secondary antibody (Sigma-Aldrich). HRP was detected via autoradiography after the addition of the substrate SuperSignal West Dura (Pierce).

\section{Phosphothreonine Western blot.}

A panel of antibodies (Phosphothreonine detection kit; Calbiochem, San Diego, CA; U.S.A.) was tested for their ability to detect phosphothreonine-containing proteins in wholewheat leaf extract. A 3-cm leaf section was ground with a mortar and pestle in $500 \mu \mathrm{l}$ of IP grinding buffer ( $20 \mathrm{mM}$ Tris- $\mathrm{HCl}$, pH 7.5; 1 mM EDTA; $150 \mathrm{mM} \mathrm{NaCl}$; and 1\% [vol/vol] Triton $\mathrm{X}-100$ ) (Boyes et al. 1998) + $1 \mathrm{mM}$ phenylmethylsolfonylfluoride (Sigma-Aldrich) + 1:100 HALT phosphatase inhibitors. Lysate $(40 \mu \mathrm{l})$ was resolved on an SDS-PAGE gel, proteins were transferred to nitrocellulose, and blots blocked overnight in blocking buffer $(1 \times$ phosphate-buffered saline [PBS], 3\% bovine serum albumen, 1\% PEG-4000, 1\% PVP10 , and $0.1 \%$ Tween-20). Antibodies were added at $0.1 \mu \mathrm{g} / \mathrm{ml}$ in blocking buffer and incubated with the blot for $2 \mathrm{~h}$. Blots were washed three times with PBS/0.05\% Tween-20 and incubated for $1 \mathrm{~h}$ with a 1:1,000 dilution of anti-mouse HRP-conjugated secondary antibody (Pierce). The 14B3 mouse mono- 
A

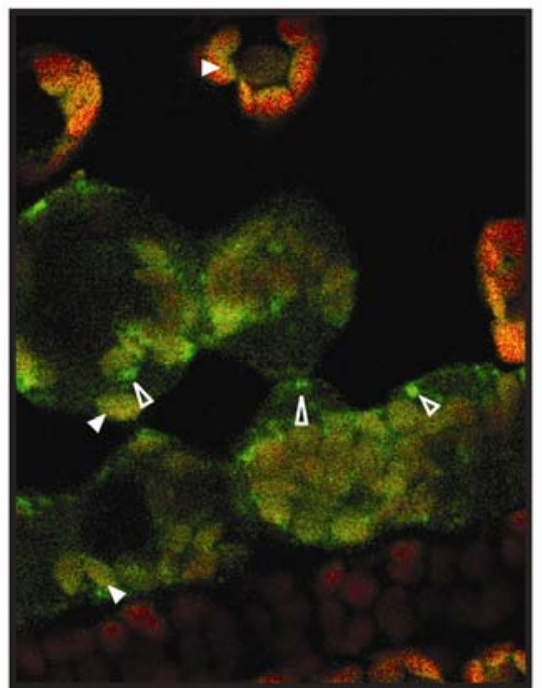

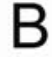

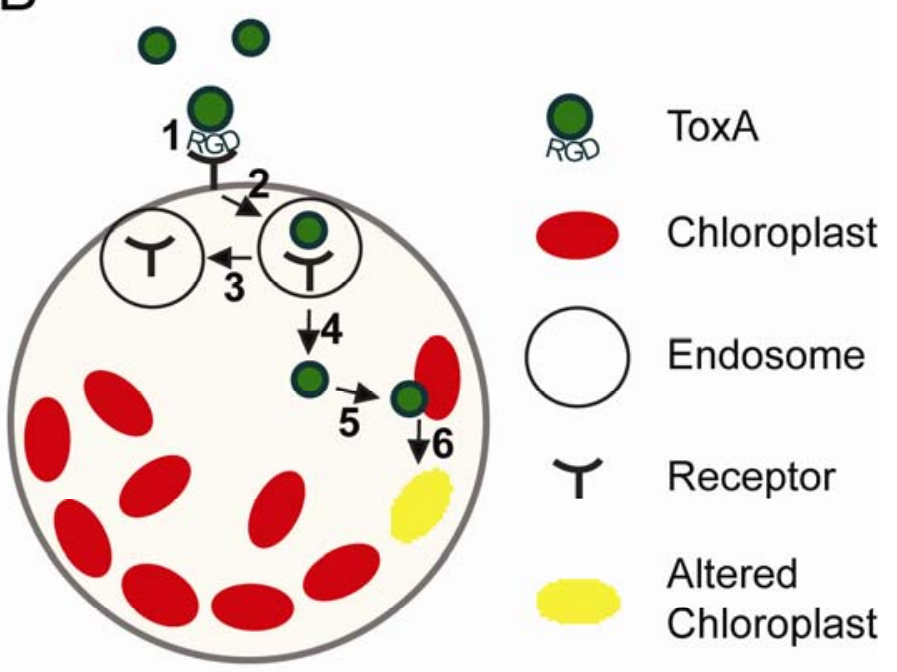

Fig. 6. Working model of ToxA function in planta. A, Confocal microscopy of green fluorescent protein (GFP)-ToxA-treated sensitive wheat mesophyll cell. Overlay of channels detecting GFP-ToxA (green fluorescence) and chloroplast autofluorescence (red). GFP-ToxA can be seen in the cytoplasm associated with chloroplasts (closed triangle) and in cytoplasmic compartments (open triangle) (Manning and Ciuffetti 2005). B, Working model of ToxA function in planta. 1, ToxA binds to high-affinity receptor via the RGD-containing, solvent-exposed loop; 2, ToxA/receptor complex internalized into endosome; 3 , dissolution of ToxA/receptor complex and recycling of receptor to membrane; 4, ToxA escapes endosome and enters cytosol; 5, ToxA binds to chloroplast and alters function; and 6, chloroplast function irreversibly altered leading to cell death.

clonal antibody was selected for use because it detected more proteins than any other antibody tested. To test for phosphorylated His-ToxA, three 3-cm sections of Katepwa leaves were infiltrated with $2 \mu \mathrm{M}$ His-ToxA and incubated for $2,4,6$, and $8 \mathrm{~h}$ in a growth chamber. Treated leaf sections were ground in $2 \mathrm{ml}$ of grinding buffer per $1 \mathrm{mM}$ phenylmethylsulfonyl fluoride (PMSF) plus 1:100 HALT phosphatase inhibitors, filtered through a $100-\mu \mathrm{m}$ Nitex filter, and frozen at $-20^{\circ} \mathrm{C}$. Samples were thawed and spiked with PMSF and HALT, and $20 \mu \mathrm{l}$ of Ni-NTA beads were added and incubated for $1 \mathrm{~h}$ on a rotator at $4^{\circ} \mathrm{C}$. Beads were washed three times with $1 \times \mathrm{NiBB}$ buffer plus 1:100 HALT phosphatase inhibitors and eluted with $20 \mu \mathrm{l}$ of $1 \times \mathrm{NiBB}$ plus $500 \mathrm{mM}$ imidazole. Samples were heated to $90^{\circ} \mathrm{C}$ for $5 \mathrm{~min}$, separated on a $13 \%$ SDS-PAGE gel, and blotted as described above. Western blot analysis with ToxA antiserum was performed as described above.

\section{Protease protection assay.}

Protease protection assays were done as described by Manning and Ciuffetti (2005) except that the removal of intercellular wash fluid was not performed. The times of protease treatment post toxin treatment were 2 and $10 \mathrm{~h}$ depending on the experiment. Western blotting was performed as described above.

\section{ACKNOWLEDGMENTS}

We would like to thank I. Pandelova and K. Skinner for helpful discussions. This project was supported by the National Research Initiative of the United States Department of Agriculture Cooperative State Research, Education and Extension Service, grant numbers 2003-35319-13476 and 2006-3519-17256 to L. M. Ciuffetti and, in part, from a grant to L. M. Ciuffetti and P. A. Karplus (MCB-0488665) from the National Science Foundation.

\section{LITERATURE CITED}

Anderson, J. A., Effertz, R. J., Faris, J. D., Francl, L. J., Meinhardt, S. W., and Gill, B. S. 1999. Genetic analysis of sensitivity to a Pyrenophora tritici-repentis necrosis-inducing toxin in durum and common wheat.
Phytopathology 89:293-297.

Ballance, G. M., Lamari, L., and Bernier, C. C. 1989. Purification and characterization of a host-selective necrosis toxin from Pyrenophora tritici-repentis. Physiol. Mol. Plant Pathol. 35:203-213.

Ballance, G. M., Lamari, L., Kowatsch, R., and Bernier, C. C. 1996. Cloning, expression and occurrence of the gene encoding the Ptr necrosis toxin from Pyrenophora tritici-repentis. Mol. Plant Pathol. 1996/1209ballance/index.htm. Published online.

Baluska, F., Samaj, J., Wojtaszek, P., Volkmann, D., and Menzel, D. 2003. Cytoskeleton-plasma membrane-cell wall continuum in plants. Emerging links revisited. Plant Physiol. 133:482-491.

Boyes, D. C., Nam, J., and Dangl, J. L. 1998. The Arabidopsis thaliana $R P M 1$ disease resistance gene product is a peripheral plasma membrane protein that is degraded coincident with the hypersensitive response. Proc. Natl. Acad. Sci. U.S.A. 95:15849-15854.

Bryan, G. T., Wu, K. S., Farrall, L., Jia, Y., Hershey, H. P., McAdams, S. A., Faulk, K. N., Donaldson, G. K., Tarchini, R., and Valent, B. 2000. tA single amino acid difference distinguishes resistant and susceptible alleles of the rice blast resistance gene Pi-ta. Plant Cell 12:2033-2046.

Ciuffetti, L. M., and Tuori, R. P. 1999. Advances in the characterization of the Pyrenophora tritici-repentis-Wheat interaction. Phytopathology 89:444-449.

Ciuffetti, L. M., Tuori, R. P., and Gaventa, J. M. 1997. A single gene encodes a selective toxin causal to the development of tan spot of wheat. Plant Cell 9:135-144.

Ciuffetti, L. M., Francl, L. J., Ballance, G. M., Bockus, W. W., Lamari, L., Meinhardt, S. W., and Rasmussen, J. B. 1998. Standardization of toxin nomenclature in the Pyrenophora tritici-repentis/wheat interaction. Can. J. Plant Pathol. 20:421-424.

De Wolf, E. D., Effertz, R. J., Ali, S., and Francl, L. J. 1998. Vistas of tan spot research. Can. J. Plant Pathol. 20:349-444.

Dubery, I. A., and Meyer, R. 1995. Specific binding of a Verticillium dahliae phytotoxin to protoplasts of cotton, Gossypium hirsutum. Plant Cell Rep. 15:777-780.

Faris, J. D., Anderson, J. A., Francl, L. J., and Jordahl, J. G. 1996. Chromosomal location of a gene conditioning insensitivity in wheat to a necrosis-inducing culture filtrate from Pyrenophora tritici-repentis. Phytopathology 86:459-463.

Fling, S. P., and Gregerson, D. S. 1986. Peptide and protein molecular weight determination by electrophoresis using a high-molarity Tris buffer system without urea. Anal. Biochem. 155:83-88.

Flor, H. H. 1971. Current status of the gene-for-gene concept. Annu. Rev. Phytopathol. 9:275-296.

Gamba, F. M., Lamari, L., and Brule-Babel, A. L. 1998. Inheritance of race-specific necrotic and chlorotic reactions induced by Pyrenophora tritici-repentis in hexaploid wheats. Can. J. Plant Pathol. 20:401-407. 
Geldner, N., and Jurgens, G. 2006. Endocytosis in signalling and development. Curr. Opin. Plant Biol. 9:1-6.

Glazebrook, J. 2005. Contrasting mechanisms of defense against biotrophic and necrotrophic pathogens. Annu. Rev. Phytopathol. 43:205-227.

Gouget, A., Senchou, V., Govers, F., Sanson, A., Barre, A., Rouge, P., Pont-Lezica, R., and Canut, H. 2006. Lectin receptor kinases participate in protein-protein interactions to mediate plasma membrane-cell wall adhesions in Arabidopsis. Plant Physiol. 140:81-90.

Lamari, L., Strelkov, S., and Yahyaoui, A. 2002. Physiologic variation in tan spot of wheat. Pages 24-27 in: Fourth Int. Wheat Tan Spot and Spot Blotch Workshop, Bemidji, MN, U.S.A.

Lamari, L., Strelkov, S., Yahyaoui, A., Orabi, J., and Smith, R. B. 2003. The identification of two new races of Pyrenophora tritici-repentis from the host center of diversity confirms a one-to-one relationship in tan spot of wheat. Phytopathology 93:391-396.

Lee, J., Klessig, D. F., and Nurnberger, T. 2001. A harpin binding site in tobacco plasma membranes mediates activation of the pathogenesisrelated gene HIN1 independent of extracellular calcium but dependent on mitogen-activated protein kinase activity. Plant Cell 13:1079-1093.

Manning, V. A., and Ciuffetti, L. M. 2005. Localization of Ptr ToxA produced by Pyrenophora tritici-repentis reveals protein import into wheat mesophyll cells. Plant Cell 17:3203-3212.

Manning, V. A., Andrie, R. M., Trippe, A. F., and Ciuffetti, L. M. 2004. Ptr ToxA requires multiple motifs for complete activity. Mol. PlantMicrobe Interact. 17:491-501.

Manning, V. A., Hardison, L. K., and Ciuffetti, L. M. 2007. Ptr ToxA interacts with a chloroplast-localized protein. Mol. Plant-Microbe Interact. 20:168-177.

Meinhardt, S. W., Cheng, W., Kwon, C. Y., Donohue, C. M., and Rasmussen, J. B. 2002. Role of the arginyl-glycyl-aspartic motif in the action of Ptr ToxA produced by Pyrenophora tritici-repentis. Plant Physiol. 130:1545-1551.

Murphy, A. S., Bandyopadhyay, A., Holstein, S. E., and Peer, W. A. 2005. Endocytotic cycling of PM proteins. Annu. Rev. Plant Biol. 56:221-251.

Nurnberger, T., Nennstiel, D., Jabs, T., Sacks, W. R., Hahlbrock, K., and Scheel, D. 1994. High affinity binding of a fungal oligopeptide elicitor to parsley plasma membranes triggers multiple defense responses. Cell 78:449-460.

Robatzek, S., Chinchilla, D., and Boller, T. 2006. Ligand-induced endocytosis of the pattern recognition receptor FLS2 in Arabidopsis. Genes Dev. 20:537-542.
Ruoslahti, E., and Pierschbacher, M. D. 1986. Arg-Gly-Asp: a versatile cell recognition signal. Cell 44:517-518.

Russinova, E., Borst, J. W., Kwaaitaal, M., Cano-Delgado, A., Yin, Y., Chory, J., and de Vries, S. C. 2004. Heterodimerization and endocytosis of Arabidopsis brassinosteroid receptors BRI1 and AtSERK3 (BAK1). Plant Cell 16:3216-3229.

Samaj, J., Read, N. D., Volkmann, D., Menzel, D., and Baluska, F. 2005. The endocytic network in plants. Trends Cell Biol. 15:425-433.

Sarma, G. N., Manning, V. A., Ciuffetti, L. M., and Karplus, P. A. 2005. Structure of Ptr ToxA: an RGD-containing host-selective toxin from Pyrenophora tritici-repentis. Plant Cell 17:3190-3202.

Stock, W. S., Brule-Babel, A. L., and Penner, G. A. 1996. A gene for resistance to a necrosis-inducing isolate of Pyrenophora tritici-repentis located on 5BL of Triticum aestivum cv. Chinese spring. Genome 39:598-604.

Strelkov, S. E., and Lamari, L. 2003. Host-parasite interaction in tan spot [Pyrenophora tritici-repentis] of wheat. Can. J. Plant. Pathol. 25:339-349.

Suzuki, N., Hosokawa, D., Matsuura, Y., Kikuchi, A., and Omura, T. 1999. In vivo and in vitro phosphorylation of rice dwarf phytoreovirus Pns12 cytoplasmic nonstructural protein. Arch. Virol. 144:1371-1380.

Tomas, A., Feng, G. H., Reeck, G. R., Bockus, W. W., and Leach, J. E. 1990. Purification of a cultivar-specific toxin from Pyrenophora triticirepentis, causal agent of tan spot of wheat. Mol. Plant-Microbe Interact. 3:221-224.

Tsumoto, K., Ejima, D., Kumagai, I., and Arakawa, T. 2003. Practical considerations in refolding proteins from inclusion bodies. Protein Expr. Purif. 28:1-8

Tuori, R. P., Wolpert, T. J., and Ciuffetti, L. M. 1995. Purification and immunological characterization of toxic components from cultures of Pyrenophora tritici-repentis. Mol. Plant-Microbe Interact. 8:41-48.

Tuori, R. P., Wolpert, T. J., and Ciuffetti, L. M. 2000. Heterologous expression of functional Ptr ToxA. Mol. Plant-Microbe Interact. 13:456-464.

Wang, Q., Sullivan, R. W., Kight, A., Henry, R. L., Huang, J., Jones, A. M., and Korth, K. L. 2004. Deletion of the chloroplast-localized Thylakoid formation1 gene product in Arabidopsis leads to deficient thylakoid formation and variegated leaves. Plant Physiol. 136:3594-3604.

Wolpert, T. J., Dunkle, L. D., and Ciuffetti, L. M. 2002. Host-selective toxins and avirulence determinants: what's in a name? Annu. Rev. Phytopathol. 40:251-285.

Zhang, H., Francl, L. J., Jordahl, J. G., and Meinhardt, S. W. 1997. Structural and physical properties of a necrosis-inducing toxin from Pyrenophora tritici-repentis. Phytopathology 87:154-160. 